\title{
BUSINESS STRATEGY DEVELOPMENT MODEL FOR APPLYING KNOWLEDGE MANAGEMENT IN CONSTRUCTION
}

\author{
Wedad ABU ADI(1) ${ }^{1}$, Mohammed HIYASSAT ${ }^{(1)}$, Natalija LEPKOVA (D2* \\ ${ }^{1}$ Civil Engineering Department, The University of Jordan, Amman, Jordan \\ ${ }^{2}$ Department of Construction Management and Real Estate, Vilnius Gediminas Technical University, \\ Vilnius, Lithuania
}

Received 3 August 2020; accepted 19 March 2021

\begin{abstract}
This study aims at developing a knowledge management (KM) model that construction companies can apply for effective knowledge management implementations in their businesses. In developing the proposed model, a mixed methodology of analysing related literature and identifying the gaps in some existing models intended for the construction industry is applied. In addition, a questionnaire and interviews approaches are conducted to prepare, enhance, strengthen and validate the developed model. The major finding of this study is proposing a new KM model - named as BAN model - that fits potential conditions for construction contracting firms, especially enterprises that are small in size and nonadopting KM. The developed model comprises six main stages: (1) preliminary stage; (2) development of an organizational strategy stage; (3) start-up stage; (4) implementation stage; (5) monitoring and evaluation stage; and (6) derivation of short- and long-term KM values. The proposed model is capable of filling and solving the gaps in existing knowledge management models and defining major success factors in KM implementation. The benefits of the proposed model include the enhancement of the KM implementation process, facilitation of the decision-making process, attainment and maintenance of competitive advantages, improvement of innovation, and continuance of effective KM performance.
\end{abstract}

Keywords: knowledge management, construction firms, construction industry, KM model, KM values, business strategy.

\section{Introduction}

Construction companies operate in a highly competitive environment, and to maintain their sustainability, construction firms need to continuously improve their performance through a knowledge management $(\mathrm{KM})$ approach. The repository of knowledge requires management processes for effectively capturing, storing, and reutilizing knowledge and ensuring high-quality products and services through the elimination of poor-quality costs (Almomani et al., 2019; Kivrak et al., 2014). According to Surbakti (2015), KM - as a tool and framework for creating and sharing knowledge - is used for solving problems and making decisions.

Capturing, storing, and sharing existing knowledge provide historical knowledge and lessons for future projects in organizations (Guribie \& Tengan, 2019; Almarshoudi et al., 2018). The integration of different experiences and forms of expertise in a variety of disciplines in problem solving constitutes the most effective and efficient approach in decision-making processes (Ahmad et al.,
2008). However, the systematic sharing of the knowledge of the gained experience within the sector is missing (Arif et al., 2017; Yousef \& Abu Baker, 2012). Decision-making in the construction industry is typically described as a process based on experience rather than on a scientific approach. This type of decision making is causing a concern that the loss of experienced experts and employees results in the deterioration of the quality and efficiency in the industry (Yousef \& Abu Baker, 2012).

Recently, technological development in the construction industry provides a significant impetus to the use of modern techniques and methods, but it could not successfully address the recurrence of previous problems and errors in an efficient and effective manner and hence prevent the adverse effects of increased project costs and work delays due to unforeseen fluctuations in the economy and politics (Mohammad \& Anumba, 2006). Arif et al. (2015) assert that one of the principal problems confronting the construction industry in developing countries is the lack

*Corresponding author. E-mail: natalija.lepkova@vilniustech.lt 
of a specific framework, method, or even an approach for learning from other completed and non-completed projects, facilitating knowledge sharing, and recording the lessons learned from these projects. In particular, the lack of $\mathrm{KM}$ implementation in some countries is one of the critical factors affecting the construction industry and a major cause of many construction problems (Arif et al., 2015).

Consequently, the main goal of this study is to develop a knowledge management model for enhancing the implementation of effective KM in the construction industry. To achieve this goal, intensive study and analyses on related literature reviews and existing KM model has conducted, also a questionnaire is used to define critical success factors (CSFs) that underline implementing KM within construction industry. The significance of the study is to develop guidance on KM, which can help construction contracting firms to effectively implement a KM framework.

\section{Literature review}

The research relies on the reviewing KM literature in order to support the research work and provide a foundation in developing the proposed model. This section provides a brief review of CSFs of KM in construction, including the tools and benefits of KM as well as the barriers facing $\mathrm{KM}$ in construction. Moreover, it reviews in details some of existing KM models in construction - the CLEVER, IMPaKT, SeLEKT, and Guribie-Tengan KMIF models.

\subsection{Knowledge management in construction}

The construction industry deals with a large number of stakeholders with different levels and areas of knowledge, including partners, employees, clients, contractors, subcontractors, suppliers, competitors, and market (Yusof et al., 2019). Therefore, having a structured system of KM and a proper allocation of its resources is of crucial importance (Davenport \& Prusak, 1998, as cited in Robinson et al., 2005).

The construction industry is a knowledge-based industry (Li et al., 2019) that combines explicit and tacit knowledge (Anumba et al., 2005). On the one hand, explicit knowledge is in the form of contract documentations, construction techniques, etc. The design sketches, $3 \mathrm{D}$ modeling, and testing procedures are also considered to be part of explicit knowledge. On the other hand, tacit knowledge is expressed through tendering skills, cost estimation, and interaction with clients, project teams, clients, etc. Tacit knowledge is a crucial type of knowledge in the construction industry, which differentiates the experience and background of practitioners (Yuan, 2011). Tacit knowledge provides a construction company with a competitive edge (Feng et al., 2017). However, sharing and transferring tacit knowledge in construction industry is considered as a critical task due to the lack of understanding how to transfer and drive tacit knowledge (Saini et al., 2018).
According to Anumba et al. (2005), KM tools categorized as KM techniques or non-IT tools such as face-toface interaction, training, and brainstorming. This type of $\mathrm{KM}$ tool is important to all organizations due to its availability, simplicity, and nature of focusing on tacit knowledge. Moreover, KM technologies refer to IT tools that are closely integrated and aligned with KM strategies (Okere, 2017). Bhatt (2001) underscores that IT helps organizations to convert data to information and deal with new, unexpected problems in the constantly evolving business environment.

Arif et al. (2017) maintain the CSFs that affect knowledge sharing (KS) within construction companies. These factors include the importance and the role of (1) systems and initiatives that guide to the trust growth among colleagues and employees through improving social and formal activities, (2) management factor which include leadership, motivation, organizational structure and management commitment, and (3) communication factor which include communication technology, social network, gender differences and collective achievement.

Dang et al. (2018) identified 32 key knowledge enabling factors (KEFs) and 10 organizational effectiveness outcomes (OEOs) specifically for knowledge management. Dang and Le-Hoai (2019) in later research related knowledge creation factors (KCFs) to construction organizations' effectiveness, which can be measured by different effectiveness outcomes.

Deepak and Mahesh (2019) developed a knowledgebased safety culture questionnaire and examined its validity and reliability for construction industry in the Indian context. Hoła et al. (2015) presented an IT model of a Knowledge Map which supports knowledge management in a construction enterprise. Lin (2014) proposed a new and practical methodology to capture and represent construction project knowledge by using a Building Information Modeling (BIM) approach.

\subsection{Benefits and barriers of knowledge management in the construction industry}

Robinson et al. (2005) argue that the benefits resulting from the application of KM in the construction industry are not immediately recognized. In their book, Anumba et al. (2005) summarize the following benefits of KM implementation: (1) improvement of organizational performance (i.e., efficiency is achieved through reduced working time by assuming the best-practice solution); (2) enhancement of the execution of construction projects; (3) improvement of the delivery of construction projects through lessons learned; (4) facilitation of knowledge transfer across stakeholders, organizations, and disciplines; (5) reduction of the redundancy of past problems; (6) improvement of the effectiveness and efficiency of response to client needs; (7) sharing of lessons learned and best practices within organizations; (8) enhancement of agility and responsiveness to organizational changes confronting construction firms; and (9) reduction of risks due 
to the expansion of the knowledge base as well as the alleviation of uncertainties.

Among the chief barriers to KM in the construction industry are the dynamics and uniqueness of construction projects and complexity of applying a best practice or a problem solution to projects (i.e., users may have relevant and similar problems but different project types and characteristics) (Ahmad, 2010; Arif et al., 2017; Okere, 2017). Other obstacles include shortage of time, lack of commitment of senior management, absence of leadership support, inadequacy of organizational culture and structure, deficiency in IT infrastructure, influence of the internal and external environments, inconsistency in priorities, and more emphasis on individuals than on teams (Robinson et al., 2005). Additionally, behavioral and personal attitudes could pose a significant barrier, in which employees are reluctant to share the knowledge that they consider as their personal intellectual property (Lin et al., 2007; Holste \& Fields, 2010). Insufficient funding also standouts as a major barrier among achievement of KM implementation (Yusof et al., 2019). Hari et al. (2005) estimate that $99 \%$ of the problems of construction firms in the UK are due to the lack of awareness of the importance of applying a KM approach within organizations, which is also affirmed by Okere (2017).

However, the primary impediments to KM implementation in the construction industry are the multi-disciplinary nature of projects and difficulty of knowledge sharing and dissemination between stakeholders (Anumba et al., 2005). A common practice in the construction industry is the poor retention of knowledge, including technical solutions and best practices, as such knowledge is based on informal collaboration and communication (Kamara et al., 2002b).

\subsection{Existing knowledge management models in the construction industry}

Multiple KM models and frameworks have been developed to meet the distinct requirements of the construction industry. Among the KM models that have been recognized and implemented in the construction industry are the CLEVER, IMPaKT, SeLEKT, and Guribie-Tengan KMIF models. Each will be discussed next.

\subsubsection{CLEVER approach}

Kamara et al. (2002a) developed the Cross-sectorial LEarning in the Virtual EnteRprise (CLEVER) approach for the manufacturing and construction industry. The model consists of four stages. The first stage of the CLEVER approach involves the identification of the KM problem in a business context. During this stage, KM activities are identified using a specific template. These activities include KM processes (e.g., generation, propagation, transfer, location, and maintenance) and determination of KM sources and user characteristics. At the second stage, and according to the organizational strategy and policy, the users define and mark the future (desired) and current situation of KM within the organization using a sliding scale of the so-called "Knowledge dimensions' guide". In addition, some concerns at this stage are determined and prioritized to define the critical migration path for each KM problem. The third stage of the CLEVER approach entails the drawing of a path to solve the problem based on an "as-is" situation to a "to-be" situation (in the future). In particular, (1) the drawing of a path for problem solving depends on the organization's resources; (2) each problem's path is independently drawn, and then the overall path of the KM problem is drawn to examine it; and (3) a set of predefined matrices or squares is established to map the current situation and move toward the desired future situation. The fourth stage is highly dependent on the previous stage. After defining each problem's path, an appropriate $\mathrm{KM}$ process(es) is selected from a standard list of KM processes. Furthermore, this final stage requires the identification of any resistors and/or enablers within the organization, who affect the implementation of the selected process.

A review of the CLEVER stages indicates that this approach converts mysterious and uncertain KM problems to specific issues, thereby facilitating the selection of an appropriate process for identifying and solving problems. However, given the multi-dimensional nature of $\mathrm{KM}$ problems, a system that constructs situations based on the idea of "if-then-or-else" is deemed to be inappropriate for experts to address these problems.

\subsubsection{IMPaKT approach}

Robinson el al. (2004) developed the IMPaKT (Improving Management Performance through Knowledge Transformation) model which consists of three stages. Stage 1 involves the development of a business strategy and a plan of business improvement; it is a result of four main steps: (1) identifying a problem and specifying knowledge dimensions; (2) defining the external drivers (e.g., downsizing, innovation needs, and expansion), organizational objectives, and internal CSFs (e.g., employees and satisfaction of stakeholders); (3) measuring the progress and performance to confirm the achievement of strategic goals and objectives and monitor the performance progress; and (4) detecting performance gaps by determining and comparing the current scores with target scores.

The second stage aims to ascertain whether KM dimensions exist for current business problems and align the KM plan with the organizational strategy. In this stage, users can obtain the required information using so-called "skills yellow pages" and thus procure the appropriate technical consultation from experts within the organization. Therefore, the users can select any appropriate tools and techniques from the organization's database. The third stage contains the evaluation of strategy and the influence of KM on business performance occurs at this stage. In this stage, the model suggests the use of tools such as cause-and-effect map (i.e., readiness audit), cost-benefit checklist, priority matrix, and evaluation roadmap. The 
results obtained from Stage 3 pertain to the development of a priority matrix that facilitates the identification of the worst and best performing KM initiatives, and the provision of a strategy of KM evaluation and an implementation plan of KM to confirm the effect of KM on the efficiency and effectiveness of organizational performance.

It can be noticed that the IMPaKT approach allows for the alignment of the KM approach with the organizational strategic plan and the measurement of the influence of KM initiatives on organizational performance. Although the IMPaKT approach is easy to use, it is not integrated with existing KM tools, and it is only limited to the usage of the tools within its framework.

\subsubsection{SeLEKT approach}

The Searching and Locating Effective Knowledge Tools (SeLEKT) approach developed by Anumba et al. (2005) comprises three main stages. The first stage entails the identification of the appropriate tools and the determination of the organization's KM dimensions, including the current and required ones; this stage encompasses three types of KM dimensions, namely "knowledge transfer domain", "knowledge conversion type", and "knowledge ownership form". Stage 2 encompasses identification of processes required for KM dimensions and their association with the appropriate tools. In this stage, the processes involved in the SeLEKT approach are locating, accessing, capturing, sharing, and creating the knowledge. The final stage in the SeLEKT approach entails the identification and selection of suitable commercial software after ascertaining the appropriate tools in the previous stage. However, Stage 3 has some limitations because it depends on certain factors such as the cost of software, available applications within the organization, and capacity to link tools with technological software.

Overall, the SeLEKT approach focuses on the selection of tools based on three KM dimensions. Although this approach is an easy one, it requires the capacity to identify the organizational status or the current and future according to the three aforementioned KM dimensions. The capability of linking dimensions with tools and technological software is likewise necessary. Finally, the implementation of the SeLEKT approach needs KM experts.

\subsubsection{Guribie-Tengan KMIF approach}

Guribie and Tengan (2019) developed the knowledge management implementation framework (KMIF) focusing on construction firms in Ghana initiating KM implementation for the first time. As a first step, KMIF approach sets knowledge management prioritization as a strategic objective of construction firms and incorporates it into their overall business strategy. The approach shows that firms must follow the five KM implementation processes: identify, storing, sharing, applying, and creating new knowledge process. Finally, KMIF affirms the importance of KM culture, KM infrastructure, KM technology, and a periodic measurement and assessment of knowledge management.
Although KMIF is easy to use, it relies on the challenges faced by Ghanaian construction industry. In addition, KMIF shows a unidirectional implementation of knowledge management; it does not cover risk management, monitoring and controlling, evaluation, making feedbacks and updates, and obtaining outcome values of implementing KM through its framework.

In summary, the highlights of the evaluation obtained from the above analysis of the four models are as follows:

- The CLEVER, IMPaKT, and SeLEKT models are lacking specifics on the roles of data workers, KM team, and $\mathrm{KM}$ end users.

- The CLEVER, SeLEKT and KMIF models suggest that $\mathrm{KM}$ activities and processes are to be performed in a sequence defined by the model. However, this case is relatively untrue, as some $\mathrm{KM}$ activities and processes could be conducted simultaneously in parallel with others.

- The CLEVER, IMPaKT, and SeLEKT models offer insufficient consideration to management support, culture of employees and organization, and other factors.

- The CLEVER, SeLEKT and KMIF models neglect the dynamic nature of knowledge and the need to update existing knowledge.

\section{Research method}

A mixed methodology was adopted in the investigation of Jordanian construction contracting companies that reflect similar conditions to those who have a small or a nonexistent KM adoption. The mixed methodology encompassed (1) a literature review to obtain the required background information on existing KM models in the construction industry and establish the theoretical foundation for the proposed model, (2) quantitative source from a questionnaire, and (3) interviews to validate the developed model. Depending on the strategy, the mixed research method is divided into three types: sequential procedures, concurrent procedures and transformative procedures. This research follows concurrent procedures in which researchers collect qualitative and quantitative data to provide complete and comprehensive research (Creswell, 2003).

The target population chosen is building and highway construction contractors companies classified - according to Jordanian Construction Association (JCCA) - as first and second-grade companies. The study population was 161: $58.4 \%$ were of first-grade contracting companies, and $41.6 \%$ of second-grade companies. A sample size of 114 was randomly selected to conduct the study.

\subsection{Litreture reviews}

As discussed earlier, relevant literature reviews used to facilitate understanding KM concept, role, barriers and significant in construction industry. It is also providing general understanding of some existing KM models used in construction; the processes, advantages and disadvantages 
of these models discussed. Literature reviews analysis is essential to strengthen and support the research topic, in which gave better understanding to KM field and defined gaps in other models in order to fill these gaps in the proposed model. This provides the theoretical foundations and enhance the outcome of the new model.

\subsection{Questionnaire survey}

To define CSFs for performing KM in small and nonadopting $\mathrm{KM}$ in construction companies, a questionnaire survey was conducted to determine: (1) the CSFs for performing $\mathrm{KM}$ in small to non-adopting $\mathrm{KM}$ in construction companies, which include factors that are vital for the success of implementing and applying KM in the construction industry; (2) the degree of importance and implementation of KM activities, tools and methods used by construction contracting firms for successful KM implementation and define which methods and activities are/ are not used currently within firms; (3) the set of important KM activities, factors and tools that will be addressed in developing the proposed model.

The questionnaire was adopted from Ahmad (2010), upon his written consent, which was conducted in a developed country in KM implementation. However, the framework has been adapted so its results reflect the degree of KM implementation and importance. As a pilot study, the questionnaire's contents are checked, evaluated, and audited by academics and KM experts.

The evaluation of implementation degree is based on three-point Likert Scale: (1) "non-implementation", (2) "small-scale implantation", and (3) "large-scale implantation". The evaluation of importance degree is based on using seven-point Likert Scale: (1) represents "not important at all", while (7) "extremely important". Additionally, the questionnaire is used to define specifications, drivers and challenges of implementing $\mathrm{KM}$, as well as to identify the CSFs that affect performing KM in construction companies. The evaluation of the environment of KM activities is based on using three-point Likert Scale: (1) is an indication for a poor level, (2) for an acceptable level and (3) for an excellent level. The evaluation of importance degree is the same as three-point Likert Scale which is used in KM activities, applications and technological tools. Furthermore, the survey asks about reasons of not implementing $\mathrm{KM}$ approach for non-KM adopter, and if there is any future intention to apply it in company.

\subsection{Reliability and validity}

Common practice is to test reliability and validity of the questionnaire before proceeding in further analysis. Reliability test is an indicator of the consistency homogeneity of results, while validity test specifies whether the questionnaire truly measured what intended to be measured (Golafshani, 2003). For this research Cronbachs' Alpha Coefficient is used to test the reliability: If the value of Cronbachs' Alpha Coefficient equals or exceeds 0.7, the measure is considered reliable (Cronbach \& Shavelson, 2004). The reliability values for each factor, in terms of importance and implementation, were checked and found that the minimum obtained value was 0.709 and the maximum value was 0.955 , since all the reliability values are larger than 0.7 , the questionnaire is reliable.

Validity splits into two types Drost (2011):

1. Content validity is defined as the qualitative type used to ensure that the indictors cover the meaning of research fundamental. It has been checked by asking $\mathrm{KM}$ experts to estimate the content validity for each factor.

2. Construct validity is the correspondence level between external factor(s) and a test measure; it is the degree of efficiently translating and transforming idea, concept, or behavior into functioning reality. Construct validity was checked by conducting Spearman test, and the results revealed that the p-values are less than 0.05 . Hence, the correlation coefficients of the factors are statistically significant meaning that the instruments used are valid.

\section{Data analysis}

Through this section the results of statistical analysis of the collected data will be provided, including calculations of the means for the levels of importance and the percent of implantation of KM activities, tools and factors for the study concerns. The level of importance indicates how important the factor, specific activity, tool is for the successful application of KM by calculating the means of responses, and the level of implementation represents the percent to which a specific activity, tool or factor is implemented.

Respondents with different years of experience participated in answering the questionnaire. Around $32.3 \%$ are managers (HR managers, project managers, head of engineering departments, and directors); $48.4 \%$ are seniors (engineers in different disciplines, HR, and team leaders); and $19.3 \%$ are juniors in different disciplines within construction contractors' firms. Tables $1 \mathrm{a}, 1 \mathrm{~b}$ and $1 \mathrm{c}$ show the analysis of responses on KM implementation activities, $\mathrm{KM}$ application activities, KM technological tools, KM environmental factors and activities, KM drivers, specifications and challenges and the opinions of non-knowledge management adopters.

The major results of data analysis are:

- For KM implementation activities, $82.8 \%$ of respondents believe that these activities are not important and their organization in prototype stage of implementing these activities, the most important activity was system implementation and the least important was system evaluation and design. Consequently, the awareness of the importance of the application of KM process and how to implement it is non-existing in most of construction companies. 
Table 1a. Results of data analysis (Importance of KM implementation)

\begin{tabular}{|c|c|c|c|c|c|c|c|c|c|c|}
\hline \multirow[b]{2}{*}{ Items } & \multirow{2}{*}{$\begin{array}{l}\text { Activities / } \\
\text { Tools / } \\
\text { Factors }\end{array}$} & \multicolumn{7}{|c|}{ Average of Importance Level (\%) } & \multicolumn{2}{|c|}{$\begin{array}{c}\text { Importance Mean } \\
\text { Values (out of 7) }\end{array}$} \\
\hline & & $\begin{array}{l}\text { Not } \\
\text { important } \\
\text { at all }\end{array}$ & $\begin{array}{l}\text { Slightly } \\
\text { important }\end{array}$ & $\begin{array}{c}\text { Moderately } \\
\text { important }\end{array}$ & Neutral & Important & $\begin{array}{c}\text { Very } \\
\text { important }\end{array}$ & $\begin{array}{l}\text { Extremely } \\
\text { important }\end{array}$ & $\begin{array}{c}\text { Mean } \\
\text { Values of } \\
\text { activities }\end{array}$ & $\begin{array}{l}\text { Overall } \\
\text { average }\end{array}$ \\
\hline \multirow{5}{*}{$\begin{array}{l}\text { KM Imple- } \\
\text { mentation } \\
\text { Activities }\end{array}$} & $\begin{array}{l}\text { System } \\
\text { Analysis }\end{array}$ & \multirow{5}{*}{-} & \multirow{5}{*}{1.7} & \multirow{5}{*}{11.3} & \multirow{5}{*}{69.8} & \multirow{5}{*}{10.3} & \multirow{5}{*}{4.3} & \multirow{5}{*}{2.6} & 4.12 & \multirow{5}{*}{4.14} \\
\hline & $\begin{array}{l}\text { System De- } \\
\text { sign }\end{array}$ & & & & & & & & 3.97 & \\
\hline & $\begin{array}{l}\text { System } \\
\text { Implemen- } \\
\text { tation }\end{array}$ & & & & & & & & 4.41 & \\
\hline & $\begin{array}{l}\text { System } \\
\text { Maintaining } \\
\text { and Moni- } \\
\text { toring }\end{array}$ & & & & & & & & 4.14 & \\
\hline & $\begin{array}{l}\text { System } \\
\text { Evaluation }\end{array}$ & & & & & & & & 4.08 & \\
\hline \multirow{4}{*}{$\begin{array}{l}\text { KM Ap- } \\
\text { plication } \\
\text { Activities }\end{array}$} & $\begin{array}{l}\text { Knowledge } \\
\text { Capturing } \\
\text { and Storing }\end{array}$ & \multirow{4}{*}{-} & \multirow{4}{*}{3} & \multirow{4}{*}{2} & \multirow{4}{*}{16} & \multirow{4}{*}{64} & \multirow{4}{*}{12} & \multirow{4}{*}{3} & 4.9 & \multirow{4}{*}{4.6} \\
\hline & $\begin{array}{l}\text { Knowledge } \\
\text { Reusing and } \\
\text { Sharing }\end{array}$ & & & & & & & & 4.6 & \\
\hline & $\begin{array}{l}\text { Knowledge } \\
\text { Reviewing } \\
\text { and Ap- } \\
\text { proving }\end{array}$ & & & & & & & & 4.4 & \\
\hline & $\begin{array}{l}\text { Using } \\
\text { Databases } \\
\text { to Create } \\
\text { Knowledge }\end{array}$ & & & & & & & & 4.4 & \\
\hline $\begin{array}{l}\text { KM Tech- } \\
\text { nological } \\
\text { Tools }\end{array}$ & $\begin{array}{l}\text { System } \\
\text { Tools }\end{array}$ & 3 & 2 & 5 & 54 & 21 & 15 & - & \multicolumn{2}{|c|}{4.47} \\
\hline \multirow{5}{*}{$\begin{array}{l}\text { Environ- } \\
\text { mental } \\
\text { Factors and } \\
\text { Activities }\end{array}$} & Culture & \multirow{5}{*}{-} & \multirow{5}{*}{3} & \multirow{5}{*}{7} & \multirow{5}{*}{15} & \multirow{5}{*}{64} & \multirow{5}{*}{9} & \multirow{5}{*}{2} & 4.55 & \multirow{5}{*}{4.5} \\
\hline & $\begin{array}{l}\text { Manage- } \\
\text { ment Lead- } \\
\text { ership and } \\
\text { Support } \\
\end{array}$ & & & & & & & & 4.62 & \\
\hline & $\begin{array}{l}\text { Information } \\
\text { Technology }\end{array}$ & & & & & & & & 4.56 & \\
\hline & $\begin{array}{l}\text { Perfor- } \\
\text { mance } \\
\text { Measure- } \\
\text { ment }\end{array}$ & & & & & & & & 3.94 & \\
\hline & $\begin{array}{l}\text { Organiza- } \\
\text { tional Infra- } \\
\text { structure }\end{array}$ & & & & & & & & 4.8 & \\
\hline $\begin{array}{l}\text { KM Driv- } \\
\text { ers }\end{array}$ & $\begin{array}{l}\text { Drivers for } \\
\text { KM }\end{array}$ & - & 5 & 5 & 7 & 68 & 12 & 3 & 4.7 & \\
\hline $\begin{array}{l}\text { KM Speci- } \\
\text { fications }\end{array}$ & $\begin{array}{l}\text { Specifica- } \\
\text { tions of the } \\
\text { KM System }\end{array}$ & - & 7 & 3 & 62 & 20 & 8 & - & 4.2 & \\
\hline $\begin{array}{l}\text { KM Chal- } \\
\text { lenges }\end{array}$ & $\begin{array}{l}\text { KM Bar- } \\
\text { riers and } \\
\text { Challenges }\end{array}$ & - & 7 & 5 & 60 & 7 & 21 & - & 4.4 & \\
\hline
\end{tabular}


Table 1b. Results of data analysis (Degree of KM implementation)

\begin{tabular}{|c|c|c|c|c|c|c|c|}
\hline \multirow{3}{*}{ Items } & \multirow{3}{*}{$\begin{array}{l}\text { Activities / } \\
\text { Tools / } \\
\text { Factors }\end{array}$} & \multicolumn{6}{|c|}{ Average of Implementation Level (\%) } \\
\hline & & \multirow{2}{*}{$\underset{(\mathrm{NI})}{\text { Not Implemented }}$} & \multirow{2}{*}{$\begin{array}{c}\text { Small Scale } \\
\text { Implementation (SI) }\end{array}$} & \multirow{2}{*}{$\begin{array}{c}\text { Large Scale } \\
\text { Implementation (LI) }\end{array}$} & \multicolumn{3}{|c|}{ Overall Average } \\
\hline & & & & & $(\mathrm{NI})$ & (SI) & (LI) \\
\hline \multirow{5}{*}{$\begin{array}{l}\text { KM } \\
\text { Implementation } \\
\text { Activities }\end{array}$} & System Analysis & 16.6 & 71.8 & 11.6 & \multirow{5}{*}{23.2} & \multirow{5}{*}{65.4} & \multirow{5}{*}{11.4} \\
\hline & System Design & 42.7 & 46.6 & 10.8 & & & \\
\hline & $\begin{array}{l}\text { System } \\
\text { Implementation }\end{array}$ & 17.7 & 69.4 & 12.9 & & & \\
\hline & $\begin{array}{l}\text { System Maintaining } \\
\text { and Monitoring }\end{array}$ & 23.9 & 65.8 & 10.3 & & & \\
\hline & System Evaluation & 15.1 & 73.3 & 11.6 & & & \\
\hline \multirow{4}{*}{$\begin{array}{l}\text { KM Application } \\
\text { Activities }\end{array}$} & $\begin{array}{l}\text { Knowledge } \\
\text { Capturing and } \\
\text { Storing } \\
\end{array}$ & 12.7 & 68.1 & 19.2 & \multirow{4}{*}{12.7} & \multirow{4}{*}{67.6} & \multirow{4}{*}{19.7} \\
\hline & $\begin{array}{l}\text { Knowledge Reusing } \\
\text { and Sharing }\end{array}$ & 7.8 & 65.1 & 27.2 & & & \\
\hline & $\begin{array}{l}\text { Knowledge } \\
\text { Reviewing and } \\
\text { Approving } \\
\end{array}$ & 18.7 & 69.0 & 12.3 & & & \\
\hline & $\begin{array}{l}\text { Using Databases to } \\
\text { Create Knowledge }\end{array}$ & 11.7 & 68.1 & 20.2 & & & \\
\hline $\begin{array}{l}\text { KM Technological } \\
\text { Tools }\end{array}$ & \multicolumn{4}{|l|}{ System Tools } & 13.7 & 61.4 & 24.9 \\
\hline \multirow{5}{*}{$\begin{array}{l}\text { Environmental } \\
\text { Factors and } \\
\text { Activities }\end{array}$} & Culture & 15.1 & 51.9 & 33.0 & \multirow{5}{*}{15.7} & \multirow{5}{*}{67.9} & \multirow{5}{*}{16.4} \\
\hline & $\begin{array}{l}\text { Management } \\
\text { Leadership and } \\
\text { Support }\end{array}$ & 11.9 & 75.4 & 12.7 & & & \\
\hline & \begin{tabular}{|l|} 
Information \\
Technology \\
\end{tabular} & 12.7 & 75.6 & 11.6 & & & \\
\hline & \begin{tabular}{|l} 
Performance \\
Measurement
\end{tabular} & 24.6 & 67.7 & 7.8 & & & \\
\hline & $\begin{array}{l}\text { Organizational } \\
\text { Infrastructure }\end{array}$ & 14.0 & 69.0 & 17.0 & & & \\
\hline KM Drivers & & & & & 6.9 & 59.8 & 33.3 \\
\hline KM Specifications & & & & & 14.1 & 74.9 & 11.0 \\
\hline KM Challenges & & & & & 11.9 & 74.5 & 13.6 \\
\hline
\end{tabular}

Table 1c. Results of data analysis (Non-KM adopters)

\begin{tabular}{|c|c|c|}
\hline \multicolumn{2}{|c|}{ Non-Knowledge Management Adopters } & Percent (\%) \\
\hline \multirow{9}{*}{ Respondents' Reasons for Not Practicing KM } & Not Interested & 7.2 \\
\hline & Unsure of its benefits & 8.2 \\
\hline & Do not understand & 10.8 \\
\hline & Have never heard off & 7.2 \\
\hline & Not needed & 1.5 \\
\hline & Top management does not support & 27.4 \\
\hline & Lack of human resources & 7.2 \\
\hline & Lack of financial resources & 18.6 \\
\hline & Lack of time & 11.9 \\
\hline \multirow{2}{*}{ Respondents Considering Implementation of $\mathrm{KM}$ in Future } & Want to implement $\mathrm{KM}$ in future & 87 \\
\hline & Do not want to implement KM & 13 \\
\hline
\end{tabular}


- In reference to KM application activities, the results show that $79 \%$ of respondents believe that these activities are important and their organization in prototype stage of implementing these activities and the most important activity was "knowledge capturing and storing", while the least two important activities were "knowledge reviewing and approving" and "using databases to create knowledge". This result means that there is an interest on initiating these activities and test their effectiveness, which will lead to establish effective KMS.

- With regard to KM technological tools, $36 \%$ of respondents believe that these activities are important and their organization in prototype stage of implementing these activities, the most important tool was "subscribing and/or password entering to define authority level" while the least important was "decision support system and/or intelligent agent". Regarding environmental activities, the analysis indicated that $75 \%$ of respondents believe that these activities are important and their organization in prototype stage of implementing these activities. The overall average 4.5 indicates that respondents believe in the importance of taking environmental activities into consideration through the adoption of KM in the construction sector. Furthermore, the questionnaire results determine the significant outcomes include that the crucial drivers of KM implementation were presenting accurate and timely knowledge to facilitate decision-making process and the least important was reducing cost and/or time to solve problems in projects, and the main reason of non-adopting KMS in construction industry is the leadership support and lack of financial resources. As a result, the main CSFs that need to be focused on through performing KM in construction companies were: leadership support, trust building, risk management, proper technology, teamwork and effective communications. According to the obtained results from analyzing questionnaire data and literature reviews, a proposed KM model will be developed in the next section.

\section{Proposed BAN model for construction contracting firms}

This section focuses on presenting the proposed model, which pertains to the development of an organizational strategy through the application of KM. For this purpose, organizational strategy development is essential to facilitate and enhance KM implementation within organizations and construction contracting firms as well as attain sustainability. In this regard, the developed model is named the "Business strategy development model for Applying kNowledge management in construction" or the BAN model. The proposed BAN model that works as a cycle in the long run through its six stages applies the major components of $\mathrm{KM}$ in construction contracting firms. The CSFs - both internal and external to the organiza- tion - that affect each stage are also discussed. Figure 1 illustrates the six stages cycle of BAN model that will be explained as follows:

\section{Stage 1: Preliminary stage}

In the preliminary stage, a taskforce technique is implemented in which the barriers, challenges, and problems confronting a company are determined through interviews, meetings, brainstorming sessions with experts and decision-makers, etc. The stakeholders are also identified in this stage. Upon accomplishing this stage, a knowledge management system (KMS) is defined to help an organization facing these challenges. The aim of this stage is to ascertain whether a company is capable of applying KMSbased on the available resources and infrastructure - and decide whether to apply the proposed KM model or keep it for future plans.

\section{Stage 2: Development of an organizational strategy}

This stage clarifies the identification and establishment of an organizational strategy, as shown in the left side of Figure 1. It consists of the following five steps: (1) set the aims and objectives of applying KMS within company's environment to help the organization to successfully implement the KM approach. (2) Prepare an appropriate strategic plan based on the SWOT (Strengths, Weaknesses, Opportunities, and Threats) analysis - through which, an organization plans to achieve its goals by matching its potential internal strengths and weaknesses with external opportunities and threats to maintain its competitive advantages. (3) Based on the strategic plan and for its effective implementation, an action plan should be devised by taskforce members that comprises sequence steps to be performed. Moreover, action plans require the establishment of specific tasks and responsibilities, identification of the duration of tasks, and allocation of the necessary resources. (4) Identify construction business processes and procedures. This step is progressively elaborated; any revisions and feedback in this step should trigger an update of the action plan accordingly. It is represented by the looping arrows that are displayed in the model. Business processes and procedures occur through the recognition of the available important knowledge within the organization, identification of the KM tools that are appropriate for applying the KM system, and conducting of interviews and questionnaire survey with employees to discuss the processes and procedures of the KM approach. (5) identify available project resources; these resources either facilitate or eliminate the successful implementation of KM.

\section{Stage 3: Start-up phase}

Having defined the organizational strategy and the need to apply KM, the next stage - start-up phase - can be undertaken. Otherwise known as the awareness phase, the startup stage represents the foundation for implementing KM within the organization; it provides the required awareness for the organization's team and individuals about the 


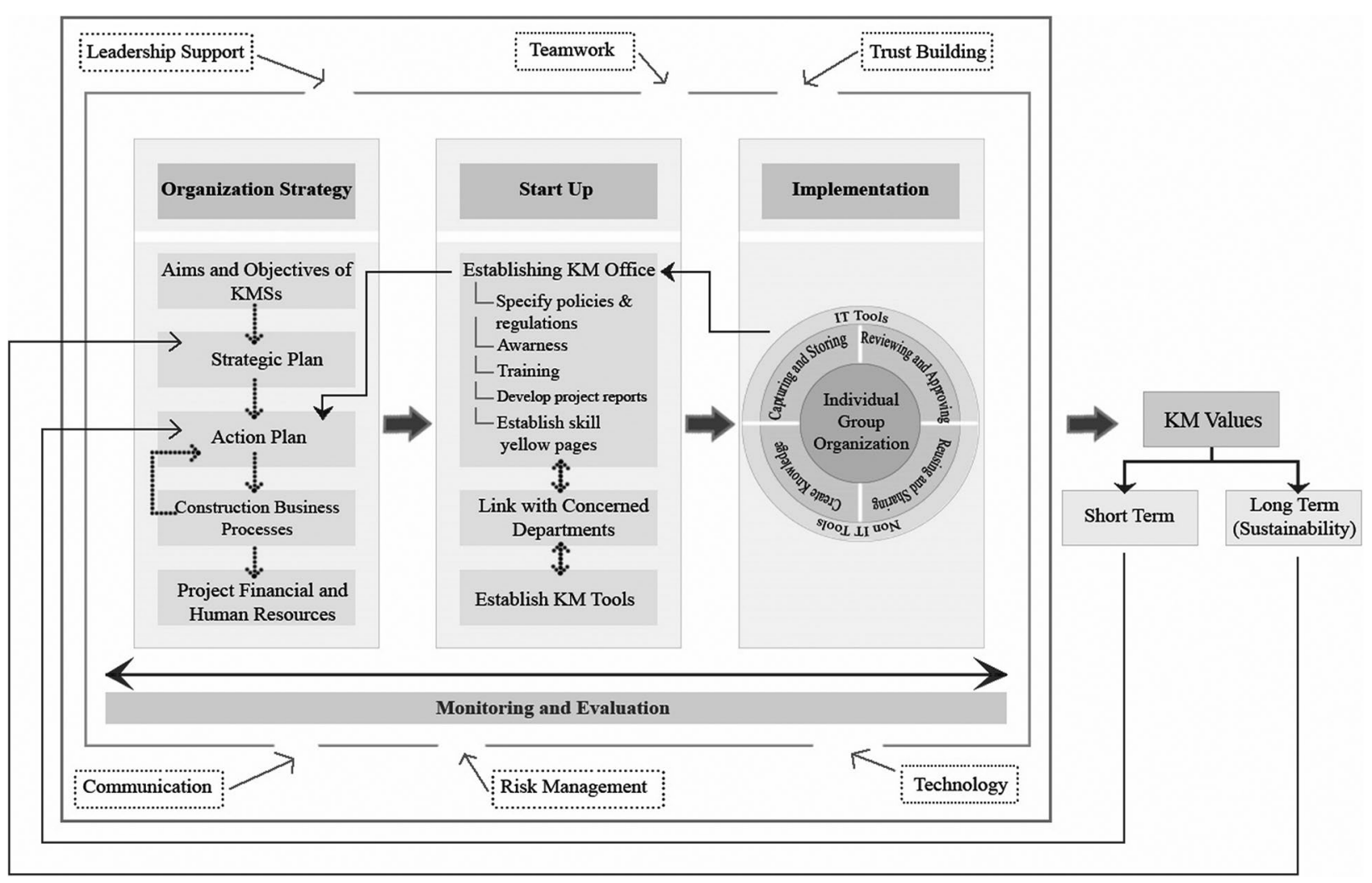

Figure 1. The proposed BAN knowledge management model for construction contractors

importance of the KM approach to quality, performance, and preservation of competitive advantages. This stage consists of three steps: establishing the KM office, linking the KM office with organizational departments, and indicating the appropriate $\mathrm{KM}$ tools.

The undertaking of a comprehensive KM implementation requires the establishment of a KM office or department within the organization's structure, which includes the KM taskforce, KM team and document controllers. The KM office plays a vital role in KM, particularly in terms of (1) providing the requisite awareness through sessions, workshops, and establishment of an e-library, among others; (2) offering training to employees to develop their skills and expertise; (3) supporting employees; (4) specifying the rules and responsibilities for applying the KM tasks; (5) preparing construction projects reports, for example, reports for internal and external best practices as well as lessons learned and reports for evaluating the progress of KM performance; (6) establishing skills yellow pages, or tools that allow users or employees to search and find other employees, consultants, and experts for consultancy purposes regarding technical issues; and (7) revising the action plan according to any updates made by the KM office.

Linking the KM office with all the departments is likewise important. For example, by linking with the human resource (HR) department, the KM office assumes a pivotal role that encompasses the following activities: (1) Determining key performance indicators (KPIs) which include activities and actions vital for monitoring, controlling, and evaluating business performance (an example of KPI is the number of accessed KM documents,) and key results indicators (KRIs) which include the outcomes obtained from many activities and actions (examples of KRI are reduction of reworks, sustainability, etc.) Thus, KPIs track activities while KRIs track values and goals. However, KRIs cannot be done without establishing KPIs. (2) Connecting employees' performance appraisal with their contribution to knowledge sharing. (3) Developing incentives and rewards that are compatible with the KM implementation. (4) Encouraging teamwork among employees. (5) Providing appropriate training. (6) Recruiting employees to fill certain knowledge gaps within the organization.

The final step occurs through building an appropriate environment by establishing the required KM tools, both IT and non-IT tools. On the one hand, IT tools include groupware, intranet, extranet, text mining, e-chatting, and knowledge bases; on the other hand, non-IT tools include face-to-face interaction, training, and brainstorming. Organizations critically need this step to (1) properly categorize and update knowledge; (2) capture, share, and store knowledge; and (3) match the KM approach with user needs and KM objectives.

\section{Stage 4: Implementation}

The implementation stage is built on a solid foundation for KM in the organization; it refers to KM execution, encompasses KM resources, application activities, and tools. 
Knowledge management resources pertain to the resources or dimensions from which knowledge is obtained. The knowledge could be acquired through interaction between individuals, groups, organization and employees. The KM application activities can be applied after the identification of the KM resources. This stage aims to establish the required knowledge database in the construction organization by capturing, storing, sharing, and reusing the knowledge created during the life cycle of projects. The first activity of KM application entails the capture and storage of the knowledge; this activity is the most important one and is conducted through a questionnaire survey with the goal of identifying the properties of KM application. Knowledge may be captured and stored through different practices such as recording and storing problem solutions in electronic software; documenting the new ideas and experiences of engineers and experts; attaching videos, text files, and pictures to clarify the contents of knowledge; and referring any obtained knowledge to its creator or resources (e.g., websites, experts, engineers, and books).

Another activity used in the BAN model involves the review and approval of the knowledge. It includes editing and publishing the approved knowledge through the intranet; reviewing and editing knowledge content by the $\mathrm{KM}$ team and office; and classifying, categorizing, and analyzing the available knowledge to facilitate the retrieval and reuse processes.

The next activity refers to the means of reusing and sharing the obtained knowledge. Different methods can be adopted for this activity, depending on the organizational culture and available tools. However, among the chief methods for sharing and reusing knowledge are the intranet or extranet and the usage of skills yellow pages that contain the names and contact details of employees for any consultation issues.

The final KM application activity in this model entails the creation of knowledge using databases. In this activity, the existing knowledge recorded in electronic copies or organizational databases is reused to create a new knowledge based on the lessons learned and the best practices of construction projects. In this regard, the new knowledge creation can be handled using the creation model theory (SECI Model) proposed by Nonaka and Takeuchi (1995). This model represents the interaction between knowledge concepts, namely: Socialization (tacit to tacit; e.g. meeting and discussion), Externalization (tacit to explicit; e.g. writing report and form organization rules), Combination (explicit to explicit; e.g. using number of reports to get needed analysis), and Internalization (explicit to tacit; e.g. learning from reports).

Based on the obtained knowledge, all of these activities of KM application may occur sequentially or even in a parallel manner. Deciding on the specific KM application activity leads to the third step of this stage, the selection of the appropriate KM system tools. KM tools differ between organizations due to their type (i.e., IT or non-IT) and availability. Some examples of KM system tools are user manuals, reporting, meetings, discussion board, mes- saging, emailing, skills yellow pages, and knowledge map. Knowledge map, which is a tool that uses a graphical presentation, provides an overview of certain issues and the linkages between elements in the existing knowledge. The knowledge created or updated during any KM application activity must be sent to the KM office to revise both the knowledge base and the action plan.

\section{Stage 5: Monitoring and evaluation}

Throughout the model stages, the monitoring and evaluation stage is a continuous process that is applied in plans, procedures, and risks, among others. Additionally, this stage involves the tracking and assessment of all the stages while updating occurs during the model implementation. It plays a vital role in investigating the improvement of business processes, updating the action plan, and examining the applicability, usefulness, and simplicity of KMS. This stage also plays a key role in monitoring and assessing the risks throughout the stages, including the processes of conducting the planning, analysis, and controlling risks throughout the stages.

\section{Stage 6: Derivation of knowledge management values}

The outcomes obtained from the application of the BAN model within contracting firms are short-term and longterm values that are described below.

\section{(a) Short-term values}

The main short-term values obtained and produced through the application of the proposed model are (but not limited to) the following:

- Savings incurred from the reduction of rework and resolution of redundant problems;

- Improvement of innovation;

- Enhancement of work quality and performance;

- Ease of retrieval of the required knowledge;

- Facilitation of the decision-making process;

- Resolution of problems with the least time and costs;

- Enhancement of relationships with stakeholders, customers, suppliers, partners, and employees; and

- Documentation of the best practices and lessons obtained from projects.

\section{(b) Long-term values (Sustainability)}

The application of the BAN model also helps to generate long-term values, including (but not limited to) the following:

- Increase in profitability;

- Improvement of productivity;

- Retention of competitive advantages;

- Enhancement of shareholder value; and

- Attainment of sustainability (i.e., maintaining KM performance, ensuring that KM becomes a routine and integrated part of organization culture).

\subsection{Critical success factors (CSFs)}

The major CSFs identified from the questionnaires and interviews encompass the six stages of the BAN model. 
In this research, the BAN model relies on the following factors: Leadership support, teamwork, trust building, effective communication, risk management, and proper technology. These CSFs can be defined based on its internal and external influences to implement KM; for example, if the proper technology factor is available within the organization - such as intranet - this will have positive internal influences, and if the technology interacted with markets, suppliers and governments then it will be external influence factor. Based on their availability and power in implementing KM values, each identified CSF will have its influence either internal to the organization, external, or a combination of both influences. These factors vary among organizations due to differences in organizational cultures. Hence, every organization should identify its own CSFs.

\subsection{Validition of the BAN model}

After developing BAN model and define its components, semi-structured interviews were conducted with $\mathrm{KM}$ academics, experienced managers, and KM professional who owned and/or worked for big companies where KMS is applied and implemented in a prototype to large scale. The aim of the interviews, which were conducted face to face with $\mathrm{KM}$ experts and academics, is to assess the model's validity and evaluate the degree of its usefulness, applicability, and simplicity. In general, the respondents confirmed its validity and agreed with model usefulness to construction companies; they also confirmed that BAN model reflected the obtained results of data analysis. They also agreed that the defined CSFs were vital to the model development.

\section{Discussion, Conclusions, and Recommendations}

As the BAN model pertains to the application of KM in construction contracting firms, it considers all of the conditions, factors, and cultural environment of these firms. The main anticipated characteristics and advantages of the new model are as follows:

1. Simple;

2. Easy to apply and understand;
3. Covers constraints, conditions of not applying KM in contracting companies;

4. Focuses on the major CSFs that confront contracting companies, which vary among countries and even companies;

5. Attempts to achieve both short-term and long-term values;

6. Increases KM awareness; and

7. Covers and solves the gaps in the reviewed existing models, as depicted in Table 2.

The CLEVER, IMPaKT, and SeLEKT models are extensively used in companies with an existing KMS. However, they cannot be utilized in companies that are not adopting KMS. Nearly all Middle East and developing countries have a few adoptions of KMS in the construction sector. On the other hand, KMIF framework relies only on challenges similar to those faced by Ghanaian construction industry in a unidirectional way.

The proposed BAN model aims to jumpstart the implementation of a KM approach in contracting companies and subsequently enhance and support KMS. The BAN model follows the main phases of project management: initiating, planning, implementation, monitoring and evaluation, and closing. After finishing the preliminary stage, the next step of the model is the definition of the aims and objectives of KMS to determine the organizational strategy. The subsequent step constitutes the foundation of KM implementation within the organization to initiate the implementation stage. The developed model is continuously improved by updating the relationships among the stages and through persistent monitoring and evaluation processes.

The unique feature of the BAN model is its focus on $\mathrm{KM}$ values. Obtaining these values in the short- and longterm results in a sustainable KM implementation. In addition, the new model covers the gaps in the existing models, such as the establishment of a KM office, identification of CSFs, inclusion of the dynamic nature of knowledge, and consideration of risk during the implementation process.

As mentioned before, this research was based on questionnaire that was adopted from Ahmad (2010). Thus, it is important to compare the results of this study with

Table 2. Gaps treatment by BAN model

\begin{tabular}{|c|c|c|}
\hline & Gaps in Existing models & Gaps' treatment by BAN model \\
\hline 1. & $\begin{array}{l}\text { CLEVER, IMPaKT and SeLEKT models are lacking the roles } \\
\text { of data workers, KM team and KM end users. }\end{array}$ & $\begin{array}{l}\mathrm{KM} \text { taskforce, } \mathrm{KM} \text { office, team and data workers play an } \\
\text { important role in the model. }\end{array}$ \\
\hline 2. & $\begin{array}{l}\text { KM activities and processes should be done in sequence } \\
\text { according to CLEVER, SeLEKT and KMIF models, and that's } \\
\text { not relatively true, some of them could be done in parallel. }\end{array}$ & $\begin{array}{l}\text { KM activities and processes in the new model can be done } \\
\text { either in a sequence or in parallel. }\end{array}$ \\
\hline 3. & $\begin{array}{l}\text { CLEVER, IMPaKT and SeLEKT models do not refer KM } \\
\text { activities to its factors such as management support and } \\
\text { culture of employees and organization. }\end{array}$ & $\begin{array}{l}\text { The new model incorporates crucial factors, namely, } \\
\text { communication skills, leadership support, trust building, } \\
\text { teamwork, technology and risk management. This is } \\
\text { important due to different organization cultures. }\end{array}$ \\
\hline 4. & $\begin{array}{l}\text { CLEVER, SeLEKT and KMIF models do not discuss the } \\
\text { dynamic nature of knowledge and the need of updating } \\
\text { existing knowledge. }\end{array}$ & $\begin{array}{l}\text { Dynamic nature of knowledge has been solved in the model, } \\
\text { through continuous feedback and updating processes of } \\
\text { activities. }\end{array}$ \\
\hline
\end{tabular}


Ahmad's results (Ahmad, 2010). Considering that Ahmad (2010) was conducted on developed country in KM implementation. The major points to derive here are:

- For KM implementation activities, the results of this study show that $82.8 \%$ of respondents evaluate that these activities as neutrally important and their organization in prototype stage of implementing these activities. While, Ahmad's results (Ahmad, 2010) show that $88 \%$ of respondents believe that these activities are important and their organization in large scale of implementing these activities.

- In reference to KM application activities, the results of this study show that $79 \%$ of respondents believe that these activities are important and their organization in prototype stage of implementing these activities. This result was compatible with Ahmad's results (Ahmad, 2010) which show that $94.1 \%$ of respondents see these activities are important and their organization in large scale of implementing these activities.

- For KM technological tools, the results of this research show that $36 \%$ of respondents believe that these activities are important and their organization in prototype stage of implementing these activities. While, Ahmad's results (Ahmad, 2010) show that $81 \%$ of respondents believe that these activities are important and their organization in large scale of implementing these activities.

- In reference to environmental activities, the results of this study show that $75 \%$ of respondents believe that these activities are important and their organization in prototype stage of implementing these activities. This result was compatible with Ahmad's results (Ahmad, 2010) which show that $88.8 \%$ of respondents consider these activities important and that their organization is in large scale of implementing these activities.

- The results of this research and results of Ahmad (2010) were compatible regarding to the most important CSFs that affect implementing KM: leadership support and financial resources.

From the obtained results, the BAN model provides a new direction for future KM research. Therefore, this study suggests the following recommendations:

- Construction contracting companies can use the BAN model as a first step of establishing knowledge management.

- Contracting companies must increasingly focus on KM tools and activities to achieve the outcomes of successful KM implementation.

- Concerned associations, governmental bodies, and societies can conduct awareness campaigns to encourage and enhance KM implementation.

- Although the developed model is targeted toward contracting companies, it can be applied to other engineering sectors in terms of their cultural environment and existing conditions.
- Other researchers can improve the BAN model to make the KM approach a routine to be applied in construction companies and enhance the usefulness of the model. Other researchers are encouraged to evaluate the BAN model.

\section{Contributions of the study}

\section{Contributions to the academic sector}

The major contributions of this research to the academic field are as follows:

- To the best of the researchers' knowledge, the BAN model in this study is the first model of its kind, which illustrates the first step of starting up with KM. Furthermore, the BAN model intends to develop KM into a working lifestyle that contracting companies can adopt.

- Research on the sharing and application of KM in developing countries is scarce. Thus, this study enhances the existing ones and seeks to inspire future research. It can be considered as a foundation for future studies to improve both company performance and work quality.

- This research has identified KM activities and CSFs in a comprehensive manner.

\section{Contributions to the contracting sector}

The key contributions of this research to the construction contracting sector are:

- This study provides companies with an opportunity to apply KM throughout the organization. Based on the analysis of questionnaires, most of the participants' companies have limited and shallow experience of KM. Many of these companies, however, have demonstrated interest in implementing $\mathrm{KM}$ in the near future.

- The BAN model provides contracting companies with the benefits (both short and long term) of implementing KM. It underscores the importance of $\mathrm{KM}$ in reducing rework, avoiding the recurrence of previous problems, and maintaining competitive advantages, among others.

- According to the results of this study, contracting companies must increase their attention to leadership and management support factors and encourage teamwork among employees who play a vital role in capturing and sharing knowledge and applying KMS.

- The BAN model can be applied in companies with small to medium KM adoption.

\section{Limitations of the study}

This study has several limitations. First, the research was only focused on contracting companies (buildings and highways). Second, some members of the target population refused to participate in the questionnaire survey. Third, some respondents indicated that these studies are 
useless and that these fundamentals only exist in theories and books. Fourth, as the KM approach is an unfamiliar subject to a sufficient number of participants, the researchers spent an ample amount of time on explanations. Other limitations, including the following: (1) many people believe that their knowledge is a personal asset that should not be shared with others. (2) Some individuals do not believe and trust in the knowledge provided or discovered by others. (3) The idea of virtual locations presents difficulties. Many projects are constructed within areas with different cultures and languages, whereas the head office is located in another area with an entirely diverse culture. This setup could affect the sharing of knowledge with the head office due to many obstacles and constraints. (4) The lack of technological infrastructure is a problem area. (5) Organizational culture poses certain challenges. Another major limitation of this study is that the KM values cannot be obtained immediately in the near future. Thus, the BAN model cannot be evaluated until it is implemented in an organization and its values in the short and long term are determined.

\section{Statement of data availability}

All the data, models, and codes generated or used during the study appear in the submitted article.

\section{Author contributions}

Wedad Abu Adi and Mohammed Hiyassat conceived the study and were responsible for the development of the proposed BAN KM model, data collection, analysis, and results interpretation. Natalija Lepkova was responsible for the review of the presented literature and data analysis.

\section{Disclosure statement}

Authors do not have any competing financial, professional, or personal interests from other parties. The authors declare no conflict of interest.

\section{References}

Ahmad, H. (2010). Development of KM model for knowledge management implementation and application in construction projects [Doctoral dissertation]. University of Birmingham, Birmingham, United Kingdom.

Ahmad, H., An, M., \& Gaterell, M. (2008). KM model to embed knowledge management activities into work activities in construction organisations. In Proceedings of 24th Annual ARCOM Conference (pp. 309-318), Cardiff, UK, Association of Researchers in Construction Management.

Almarshoudi, A., Suresh, S., \& Renukappa, S. (2018). Knowledge management practices in Oman construction sector. International Journal of Knowledge Engineering, 4, 50-54.

https://doi.org/10.18178/ijke.2018.4.1.099

Almomani, R., Al-Abbadi, L., Abu-Rumman, A. R., Abu-Rumman, A., \& Banyhamdan, K. (2019). Organizational memory, knowledge management, marketing innovation and cost of quality: Empirical effects from construction industry in Jordan. Academy of Entrepreneurship Journal, 25(3).

Anumba, C. J., Egbu, C., \& Carrillo, P. (2005). Knowledge management in construction (1st ed.). Blackwell Publishing. https://doi.org/10.1002/9780470759554

Arif, M., Al-Zubi, M., \& Gupta, A. D. (2015). Understanding knowledge sharing in the Jordanian construction industry. Construction Innovation, 15, 333-354. https://doi.org/10.1108/CI-03-2014-0018

Arif, M., Al-Zubi, M., Gupta, A. D., Egbu, C., Walton, R. O., \& Islam, R. (2017). Knowledge sharing maturity model for Jordanian construction sector. Engineering, Construction and Architectural Management, 24, 170-188.

https://doi.org/10.1108/ECAM-09-2015-0144

Bhatt, D. (2001). Knowledge management in organizations: Examining the interaction between technologies, techniques, and people. Journal of Knowledge Management, 5, 68-75. https://doi.org/10.1108/13673270110384419

Creswell, J. W. (2003). Research design: qualitative, quantitative, and mixed methods approaches (2nd ed.). Sage Publications, Inc.

Cronbach, L. J., \& Shavelson, R. J. (2004). My current thoughts on coefficient alpha and successor procedures. Educational and Psychological Measurement, 64, 391-418. https://doi.org/10.1177/0013164404266386

Dang, C. N., Le-Hoai, L., \& Kim, S. Y. (2018). Impact of knowledge enabling factors on organizational effectiveness in construction companies. Journal of Knowledge Management, 22(4), 759-780. https://doi.org/10.1108/JKM-08-2016-0350

Dang, C. N., \& Le-Hoai, L. (2019). Relating knowledge creation factors to construction organizations' effectiveness. Journal of Engineering, Design and Technology, 17(3), 515-536.

https://doi.org/10.1108/JEDT-01-2018-0002

Davenport, T. H., \& Prusak, L. (1998). Working knowledge: How organizations manage what they know. Harvard Business School Press.

Deepak, M. D., \& Mahesh, G. (2019). Developing a knowledgebased safety culture instrument for construction industry. Engineering, Construction and Architectural Management, 26(11), 2597-2613.

https://doi.org/10.1108/ECAM-09-2018-0383

Drost, E. A. (2011). Validity and reliability in social science research. Education Research and Perspectives, 38, 105-123.

Feng, W. J., Yan, C. M., Jie, F. L., \& Ju, Y. J. (2017). The construction of enterprise tacit knowledge sharing stimulation system oriented to employee individual. Procedia Engineering, 174, 289-300. https://doi.org/10.1016/j.proeng.2017.01.139

Golafshani, N. (2003). Understanding reliability and validity in qualitative research. The Qualitative Report, 8, 597-607.

Guribie, F. L., \& Tengan, C. (2019). A proposed knowledge management implementation framework for the Ghanaian construction industry. Journal of Building Construction and Planning Research, 7, 1-10.

https://doi.org/10.4236/jbcpr.2019.71001

Hari, S., Egbu, C., \& Kumar, B. (2005). A knowledge capture awareness tool: An empirical study on small and medium enterprises in the construction industry. Engineering, Construction and Architectural Management, 12, 533-567. https://doi.org/10.1108/09699980510634128

Hoła, B., Sawicki, M., \& Skibniewski, M. (2015). An IT model of a Knowledge Map which supports management in small and medium-sized companies using selected Polish construction enterprises as an example. Journal of Civil Engineering and Management, 21(8), 1014-1026.

https://doi.org/10.3846/13923730.2015.1030865 
Holste, J. S., \& Fields, D. (2010). Trust and tacit knowledge sharing and use. Journal of Knowledge Management, 14, 128-140. https://doi.org/10.1108/13673271011015615

Li, Y., Song, Y., Wang, J., \& Li, C. (2019). Intellectual capital, knowledge sharing, and innovation performance: Evidence from the Chinese construction industry. Sustainability, 11, 2713. https://doi.org/10.3390/su11092713

Lin, Y.-C. (2014). Construction 3D BIM-based knowledge management system: a case study. Journal of Civil Engineering and Management, 20(2), 186-200.

http://dx.doi.org/10.3846/13923730.2013.801887

Lin, Y., Wang, L., \& Irani, Z. (2007). Enhancing knowledge exchange through web map-based knowledge management system in construction: Lessons learned in Taiwan. Automation in Construction, 14, 94-109.

Kamara, J. M., Anumba, C. J., \& Carrillo, P. M. (2002a). A CLEVER approach to selecting a knowledge management strategy. International Journal of Project Management, 20, 205-211. https://doi.org/10.1016/S0263-7863(01)00070-9

Kamara, J. M., Augenbroe. G., Anumba, C. J., \& Carrillo, P. M. (2002b). Knowledge management in the architecture, engineering and construction industry. Construction Innovation, 2, 53-67. https://doi.org/10.1108/14714170210814685

Kivrak, S., Arslan, G., Tuncan, M., \& Birgonul, M. T. (2014). Impact of national culture on knowledge sharing in international construction projects. Canadian Journal of Civil Engineering, 41(7), 642-649. https://doi.org/10.1139/cjce-2013-0408

Mohammad, S. F., \& Anumba, C. J. (2006). Potential for improving site management practices through knowledge management. Construction Innovation, 6, 232-249. https://doi.org/10.1108/14714170610713917

Nonaka, I., \& Takeuchi, H. (1995). The knowledge-creating company: How Japanese companies create the dynamics of innovation. Oxford University Press. https://doi.org/10.1016/0024-6301(96)81509-3

Okere, G. O. (2017). Barriers and enablers of effective knowledge management: A case in the construction sector. The Electronic Journal of Knowledge Management, 15(2), 85-97.

Robinson, H. S., Carrillo, P. M., Anumba, C. J., \& Al-Ghassani, A. M. (2004). Developing a business case for knowledge management: The IMPaKT approach. Construction Management and Economics, 22, 733-743. https://doi.org/10.1080/0144619042000226306

Robinson, H. S., Carrillo, P. M., Anumba, C. J., \& Al-Ghassani, A. M. (2005). Knowledge management practices in large construction organizations. Engineering, Construction and Architectural Management, 12, 431-445. https://doi.org/10.1108/09699980510627135

Saini, M., Arif, M., \& Kulonda, D. R. (2018). Critical factors of transferring and sharing tacit knowledge within lean and agile construction processes. Construction Innovation, 18(1), 64-89. https://doi.org/10.1108/CI-06-2016-0036

Surbakti, H. (2015). Integrating knowledge management and business intelligence processes for empowering government building organization. International Journal for Computer Applications, 114, 36-43. https://doi.org/10.5120/19976-1874

Yousef, M. N., \& Abu Baker, A. H. (2012). Knowledge management and growth performance in construction companies: A framework. Procedia - Social and Behavioral Sciences, 62, 128-134. https://doi.org/10.1016/j.sbspro.2012.09.022
Yusof, M. N., Yahaya, N. M., Awang, N., Hassan, N. N. B. N., \& Cheen, K. S. (2019). The challenges in implementing knowledge management in construction industry. International Journal of Engineering and Advanced Technology (IJEAT), 8, 86-90. https://doi.org/10.35940/ijeat.E1012.0585C19

Yuan, M. (2011). An integrated knowledge management framework for managing sustainability knowledge in the Australian infrastructure sector [Doctoral dissertation]. Queensland University of Technology, Brisbane, Australia. 